\title{
Female Pattern Hair Loss
}

\author{
Ingrid Herskovitz ${ }^{1}$, Antonella Tosti ${ }^{1, *}$ \\ ${ }^{1}$ Department of Dermatology and Cutaneous Surgery, University of Miami, Miami, USA \\ *Corresponding author: Antonella Tosti, 1295 NW 14th Street, University of Miami, Hospital South Bldg, Suites K-M, FL 33136, Miami, USA. Tel: +1-3052434472, E-mail: atosti@med. \\ miami.edu.
}

Received: December 20, 2012; Revised: April 24, 2013; Accepted: May 05, 2013

\begin{abstract}
Context: Female pattern hair loss(FPHL)also known as female androgenetic alopecia is a common condition afflicting millions of women that can be cosmetically disrupting. Prompt diagnosis and treatment are essential for obtaining optimal outcome.

This review addresses the clinical presentation of female pattern hair loss, its differential diagnosis and treatment modalities.

Evidence Acquisition: A) Diffuse thinning of the crown region with preservation of the frontal hairline (Ludwig's type)

B) The "Christmas tree pattern" where the thinning is wider in the frontal scalp giving the alopecic area a triangular shaped figure resembling a christmas tree.

C) Thinning associated with bitemporal recession (Hamilton type).

Generally, FPHL is not associated with elevated androgens.

Less commonly females with FPHL may have other skin or general signs of hyperandrogenism such as hirsutism, acne, irregular menses, infertility, galactorrhea and insulin resistance. The most common endocrinological abnormality associated with FPHL is polycystic ovarian syndrome (PCOS).

Results: The most important diseases to consider in the differential diagnosis of FPHL includeChronic Telogen Effluvium(CTE), Permanent Alopecia after Chemotherapy (PAC), Alopecia Areata Incognito(AAI) and Frontal Fibrosing Alopecia (FFA). This review describes criteria for distinguishing these conditions from FPHL.

Conclusions: The only approved treatment for FPHL, which is $2 \%$ topical Minoxidil, should be applied at the dosage of $1 \mathrm{ml}$ twice day for a minimum period of 12 months. This review will discuss off-label alternative modalities of treatment including 5-alfa reductase inhibitors, antiandrogens, estrogens, prostaglandin analogs, lasers, light treatments and hair transplantation.
\end{abstract}

Keywords: Polycystic Ovary Syndrome; Minoxidil;Female;Alopecia,Therapy;Alopecia, physiopathology;Androgen antagonist, Therapeutic Use

\section{Female Pattern Hair Loss}

FPHL has been defined as nonscarring progressive miniaturization of the hair follicle, usually with characteristic pattern distribution that occurs in genetically predisposed women (1).

Female Pattern Hair Loss (FPHL) is a frequent diagnosis in the medical practice. The intention of this review is to clarify the guidelines for diagnosis and treatment and address the clinical presentation of female pattern hair loss, its differential diagnosis and treatment modalities.

The review search included Medline, Google Scholar and LILACS between 1977 and 2012. The keywords utilized were: female pattern hair loss, hair growth and development, alopecia/physiopathology, alopecia/chemically induced, polycystic ovary syndrome/diagnosis, minoxidil/ administration and dosage, alopecia/therapy, androgen antagonists/therapeutic use.

\section{Epidemiology}

Female pattern hair loss is a frequent condition. There are over 21 million women affected by FPHL in the U.S.A (2). This disease is important because of the intense emotional distress it causes by disrupting self image (3).

There are reported incidences of $12 \%$ in females around 30 years old and of $30-40 \%$ in the female population between 60 and 69 years old $(4,5)$. This condition usually manifests after puberty with variable clinical severity and rate of progression but can manifest at any age. The earlier it presents the more intense the clinical picture tends to be.

Female pattern hair loss is also termed female androgenetic alopecia because its possible association with altered androgen metabolism and familial occurence.

\section{Etiopathogenesis}

The hair follicles are constantly cycling between growth

Implication for health policy/practice/research/medical education:

This work aims to support the general physician to provide accurate diagnosis and continued care for a long term widespread disorder such as female pattern hair loss.

Copyright (C) 2013, Research Institute For Endocrine Sciences and Iran Endocrine Society; Published by Kowsar. This is an Open Access article distributed under the terms of the Creative Commons Attribution License (http://creativecommons.org/licenses/by/3.0), which permits unrestricted use, distribution, and reproduction in any medium, provided the original work is properly cited. 
and rest. The growth phase will determine the length of the hair.

Most scalp hairs (85-90\%) are in the anagen phase, which is the growth stage of the hair follicle cycle and lasts for approximately 2-6 years. Ten to fifteen percent of hairs are in the telogen phase which is the resting phase of the hair follicle cycle and lasts for about 3 months. The hair shaft sheds at the end of the telogen phase. Hair may vary in shaft diameter and length: vellus hairs are depigmented usually non-medulated, thinner and shorter than terminal hairs, which are pigmented and have a medulla. While they both undergo the entire hair cycle, the cycle is shorter for vellus hair.

In FPHL there is progressive hair follicle miniaturization and conversion of terminal follicles into vellus-like follicles. These vellus-like follicles have a shortened hair cycle because their anagen phase is reduced and produce hair shafts that are short and fine. Unlike in men, the miniaturization is not uniform and intense, therefore, except for very rare cases, there are no complete areas of baldness (4).

In some women with FPHL there is evidence of altered metabolism of androgens but excessive androgen production is not present in all cases. Rather, since serum testosterone is normal in most patients (6-8) the term Female Pattern Hair Loss is preferred over "Female Androgenetic Alopecia”. An increased sensitivity of the hair follicle to normal androgen levels can explain the onset of the disease in patients without hyperandrogenism. To further complicate the problem there are individuals with androgen insensitivity syndrome or alpha reductase deficiency, who present with patterned scalp alopecia (9). This indicates that FPHL, differently from male pattern hair loss, may develop even in the absence of androgens. A recent questionnaire based study even showed that androgen treatment can improve FPHL in some women. The study monitored for 1 year pre and postmenopausal patients for the effects of subcutaneous testosterone implants on the incidence of breast cancer. Hair thinning was assessed and $63 \%$ of patient who complained of hair thinning reported hair regrowth with treatment (10).

When androgens levels are elevated the role of these hormones is quite clear although it is noteworthy that hyperandrogenism by itself does not necessarely cause FPHL (11). The mechanism by which androgens cause hair loss has been linked to increased production of cytokines, which induce the hair to enter the telogen phase and the dermal papilla to become senescent $(12,13)$.

The genetic inheritance of FPHL is still unclear. FPHL is possibly a multigenic disease, but the causative genes are not established. The polymorphism of one of the two major susceptibility genes for male pattern hairloss, the androgen receptor gene EBA2R on the X chromosome, has been recently associated with early onset FPHL (14). The role of aromates genes CYP19A1) (15) has been reported but not confirmed in a more recent study (16). In other studies there were no associations between steroid 5-alpha-reductase isoforms genes or sex steroid hormone receptors and FPHL (17). Neither there was association with melanocortin 4 receptor gene (18).

FPHL is often precipitated and exacerbated by conditions that cause telogen effluvium, such as medications, acute stressors, weight loss, partum and hormonal therapies with proandrogenic effects like norethisterone, levornogestrel and tibolon.

The association with other skin signs of hyperandrogenism such as acne or hirsutism is an indication for extensive interdisciplinary evaluation (1).

\section{Clinical Features}

The female pattern hair loss patient usually complains of slowly progressive hair thinning (1) that may or may not be associated with increased shedding. The affected areas usually involve the vertex and upper parietal scalp and sometimes also frontoparietal areas of the head. Unike in men the frontal hair line is typically preserved and the hair miniaturization is not as severe.

Three different patterns of hair loss can be observed:

1. Diffuse thinning of the crown region with preservation of the frontal hairline (Ludwig's type) (Figure 1). The severity of this pattern can be evaluated using the 3-point Ludwig ( 19 ) scale or the 5-point Sinclair scale.

2. Frontal midline recession/breach with thinning and widening of the central part of the scalp without diffuse hair loss, best known as "Christmas tree pattern" as described by Olsen (20). This pattern also involves the superior part of the scalp but the thinning is wider in the frontal scalp giving the alopecic area a triangular shaped figure resembling a christmas tree.

3. Thinning associated with bitemporal recession (Hamilton type). This presentation has the same classical distribution of male pattern baldness: thinning evident in the lateral-frontal part of the superior scalp and vertex.

According with a study, women with Ludwig's pattern may develop an Hamilton's pattern after menopause (21). In some women, however, hair thinning is more diffuse and involves the parietal and occipital areas of the scalp, with a pattern of diffuse alopecia. These cases might impose an obstacle when in search of donor areas for hair transplantation (1). 
Herskovitz I et al.

Figure 1. FPHL: Ludwig Type

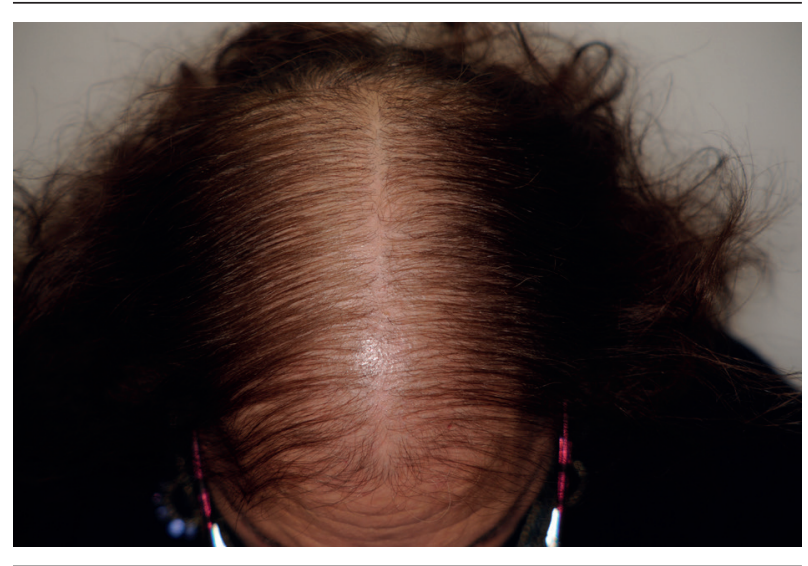

Severity: Ludwig 2/ Sinclair 4

\section{Diagnosis}

The diagnosis is mainly clinical and biopsy is usually not necessary. Dermoscopy is useful to detect early FPHL and to distinguish FPHL from other hair disorders that can cause hair thinning (22).

The hair pull test, which is a maneuver performed by the examiner that gently pulls tufts of hairs along the scalp, is usually positive in the affected scalp as miniaturization causes shortening of the hair cycle with increased telogen shedding. When positive in all scalp areas it indicates associated telogen effluvium. Dermoscopic examination of the scalp correlates with the clinical classifications of FPHL, revealing variability in the hair shaft diameter that affects at least $20 \%$ of hairs (23) and increased number of vellus hairs, parameters which are linked to follicle miniaturization (24).

Patients with FPHL may have other skin or general signs of hyperandrogenism such as hirsutism, acne, irregular menses, infertility, galactorrhea and insulin resistance, but most do not. The most common endocrinological abnormality associated with FPHL is polycystic ovarian syndrome (PCOS). Hyperandrogenism is often a common feature between the two conditions and in both, the manifestation of this hyperandrogenism may not correlate with the circulating androgen levels because total circulating testosterone is mostly bound to albumin and sex-hormone binding globulin. But even then, both conditions can be treated with anti-androgens, androgen receptor blockers and enzyme inhibitors to avoid the effects of the androgens in the target organs. Another important association with FPHL is metabolic syndrome because of increased cardiovascular risks. One study with 77 female subjects found $48.6 \%$ of the women with FPHL to also have metabolic syndrome (25) and a more recent study conducted in 1701 women in Korea, proved positive statistical association between FPHL and metabolic syndrome (26). Possible mechanisms to explain the as- sociation between these conditions are the presence of 5 alpha-reductase and DHT receptors in the vessels.

Patients must also be investigated for systemic and newly diagnosed illnessess within the past year before the signs of alopecia manifested, as well as about significant weight loss, eating habits and medications that can cause hair loss or increase androgen levels (1).

\section{Laboratory Tests}

It is important to evaluate thyroid function, ferritin and vitamin D level to exclude factors that can increase hair shedding and aggravate the disease.

Patients with a history of irregular menses, elevated body mass index or skin signs of hyperandrogenism should be referred to endocrinologists for possible PCOS. Laboratory tests utilized to evaluate androgen state are reported in Table 1.

\begin{tabular}{l}
\hline Table 1. Laboratory Tests to Exclude Androgen Excess \\
$\mathbf{5}$ alpha dehydrotestosterone \\
$\mathbf{1 7}$ beta hydroxyprogesterone \\
Androstenedione \\
\hline Dehydroepiandrosterone \\
Total testosterone/SHBG ratio \\
\hline Sex hormone-binding globulin \\
\hline
\end{tabular}

\section{Differential Diagnosis}

In our experience the most important diseases to consider in the differential diagnosis of FPHL include Chronic Telogen Effluvium (CTE), Permanent Alopecia after Chemotherapy (PAC), Alopecia Areata Incognito (AAI) and Frontal Fibrosing Alopecia (FFA).

Chronic Telogen Effluvium (CTE) is a primary idiopathic disease that most commonly affects middle aged women who complain of increased hair shedding, with bitemporal recession (Figure 2) (27). Hair thinning is not a feature of CTE and patients usually have a very good hair density despite complaining of reduction of their hair volume. There is no miniaturization $(27,28$ ) and some patients may complain of trichodynia. The cause maybe multifactorial and difficult to establish. Usually there is not a triggering factor, as in acute telogen effluvium.

CTE can be differentiated from early FPHL by dermoscopy and histology $(22,23,27)$

Some authors believe CTE tends to spontaneously improve over a decade of fluctuation of the disease, cycling every two years, according to one experimental study (29). This condition does not tend to progress to baldness. Permanent alopecia after chemotherapy (PAC) is defined as incomplete hair regrowth after chemotherapy, possibly due to hair follicle stem cell distruction. The cause remains unknown. The most commonly implicated agents are busulphan (Bu)/cyclophosphamides (Cy)- 
Herskovitz I et al.

drugs used in conditioning treatments for bone marrow transplantation (BMT) and taxanes (docetaxel, paclitaxel $(30,31)$. The frequency of PCIA varies according to agent and dose utilized for chemotherapy.

Patients have moderate to very severe hair thinning, with short miniaturized hairs. Hair thinning may be more evident on androgen-dependent scalp regions (30, 32). In one study, patients complained the hair would not grow longer than $10 \mathrm{~cm}$ and in some cases, the texture of the regrown hair would be different. The disease is irreversible and so far there has been no effective treatment (31). Alopecia Areata Incognito is a variant of Alopecia Areata $(33,34)$ characterized by severe acute thinning and hair shedding of telogen roots in different stages of maturation (33) Patients may develop classical patches of alopecia areata in the follow up. Diagnosis requires histopathological examination, but can be suggested by dermoscopy, which shows yellow dots and short regrowing hairs $(33,35)$. The prognosis is usually favorable with rapid response to steroid treatment (33).

Frontal Fibrosing Alopecia (FFA) was first described in 1994 by Kossard ( 36 ) but its frequency is recently increasing worldwide. It is a lymphocytic cicatricial/scarring alopecia that is considered a variant of lichen planopilaris (LPP) (Figure 3).

Patients are usually but not exclusively post-menopausal females (one review found the mean age to be 64 years) (37-39) who complain of slowly progressive recession of the frontal hairline. $(37,38,39)$ The temporal and parietal hairline can also be involved (38). It is also typical to see alopecia of the eyebrows and limbs (37-39). Sometimes a few scattered terminal hairs are seen in the band of recession. The new hairline shows absence of vellus and intermediate hairs, perifollicular erythema and scales around remaining terminal hairs (39).

Figure 2. CTE: Note Typical Temporal Recession.

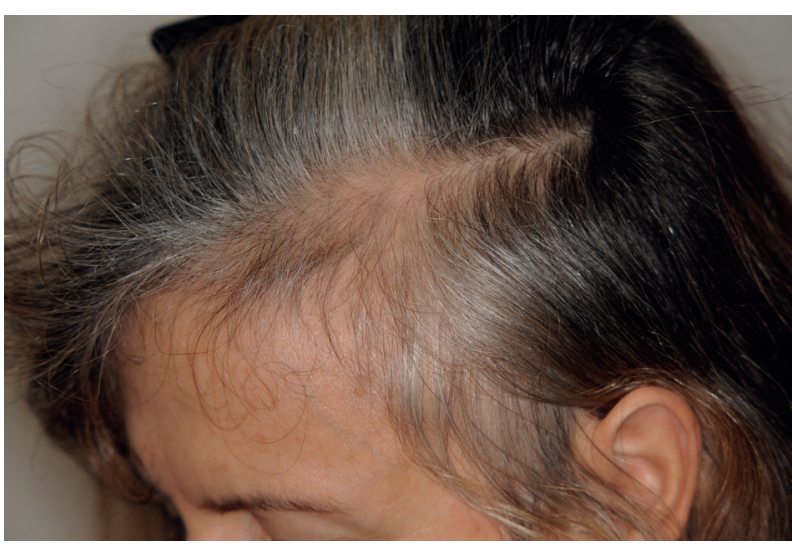

The hair density is otherwise normal
Figure 3. FFA: Scarring alopecia with recession of frontal hairline and alopecia of the eyebrows.

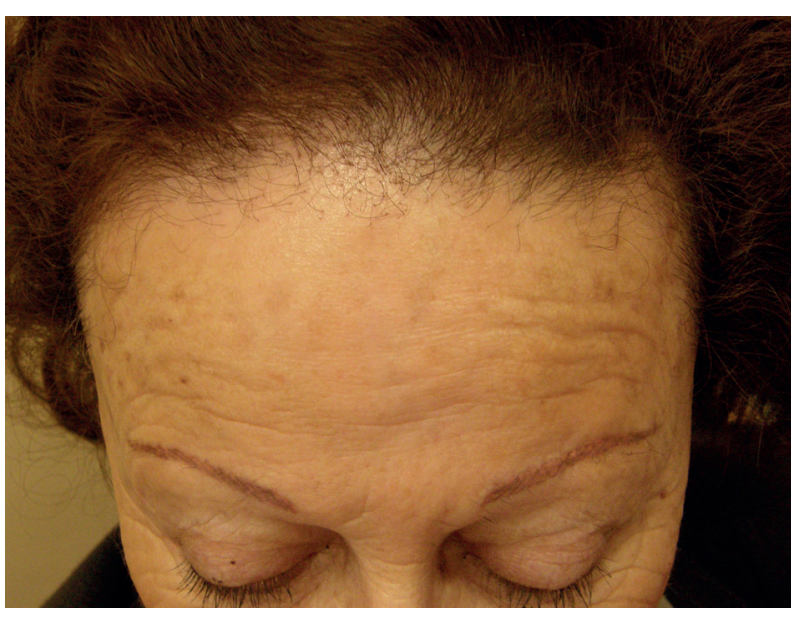

Note peripilar papules

The prevalence of this disease has been significantly increasing in the past 10 years (38) and even though no identifyable factors are to blame, this recent surge suggests that an enviromental factor can be implicated. The condition is slowly progressive and responds poorly to treatment.

\section{Treatment of FPHL}

The only medication approved for FPHL is $2 \%$ topical minoxidil. This section will however also discuss several other treatment alternatives that are possibly effective, but not approved.

\subsection{Minoxidil 2\% Solution}

This is a potassium channel opener and its mechanism of action is still unclear. It is believed that it enhances angiogenesis around the follicle by increasing the expression of vascular endothelial and hepatocytic growth factors, the latter being a hair growth promoter. It is also believed that there is activation of cyto protective prostaglandin synthase-1 (40). Minoxidil induces telogen hairs to enter the anagen phase, prolonging anagen duration (40). It increases hair count (40) and weight. Topical minoxidil solution should be applied only to the affected area of the scalp at the dosage of $1 \mathrm{ml}$ twice day (41) for a minimum period of 12 months before deciding about the efficacy. When effective, treatment should be continued indefinitely as with a chronic disease, otherwise, telogen effluvium can be triggered upon interruption. Patients should also be warned that in the first months of treatment a transient increase shed may occur. Treatment side effects are uncommon and include allergic or irritative contact dermatitis, which is more commonly related to the solution vehicle propylene glycol. This can be overcome with use of the $5 \%$ foam that does not contain this ingredient. A recent study showed that the $5 \%$ foam once a day was as effective as the $2 \%$ solution twice a 
day in female patients (42). Another possible side effect is hypertrichosis of the forehead or face, usually caused by accidental contamination or improper application.

\subsection{Anti-Androgens}

Synthetic anti-androgens are used orally to to block androgen receptor binding. They include Cyproterone acetate (not available in the US), Spironolactone and Flutamide. Studies about efficacy of Cyproterone acetate are not uniform $(43,44)$. Probably it is more effective when there is evidence of biochemical hyperandrogenism (44). Spironolactone is a potassium sparing diuretic that acts by decreasing testosterone production in the adrenal gland and by blocking the androgen receptors in the target tissues (45). Although not approved to be used in FPHL, it has been shown to be effective in the treatment of hirsutism associated with polycystic ovarian syndrome and acne $(46,47)$. It is has been used off-label as an antiandrogen for FPHL at a dosage of 50 to $200 \mathrm{mg}$ per day $(48,49)$ with better efficacy at $150 \mathrm{mg} /$ day $(50)$. One study showed equivalent efficacy in FPHL when Spironolactone was compared to Cyproterone acetate (49). Flutamide use is limited because it can cause severe liver toxicity. One study reported efficacy of Flutamide at a dosage rangeing from 62.5 to $250 \mathrm{mg}$ day, without side effects at a low dosage; results were however only based on clinical examination (51). Another study found hepatic toxic side effects even with very low doses of Flutamide (52). Overall, there is not enough evidence based data to support the routine use of antiandrogens in FPHL.

\subsection{Finasteride}

Finasteride is a type two 5 alpha-reductase enzyme inhibitor which inhibits the convertion of testosterone into dihydrotestosterone (DHT) (40). Finasteride reduces hair loss and stimulates hair regrowth by increasing hair counts in men taking $1 \mathrm{mg}$ daily (40). In women one controlled study with Finasteride 1 mg yielded no benefits on post-menopausal women (53). One uncontrolled study showed improvement in $62 \%$ of premenopausal women taking $2.5 \mathrm{mg}$ of finasteride daily associated with an oral contraceptive containing drospirenone and ethinyl estradiol (54). Several case reports, case series and small trials confirmed improvement both in pre or postmenopausal women taking 2.5 to $5 \mathrm{mg}$ of finasteride daily $(55,56)$. Response to treatment was not dependent on evidence of hyperandrogenism. Finasteride has a safe side-effect profile in men, but further controlled studies need to be conducted for extending the knowledge on its benefits and safety profile for women. Premenopausal women need to utilize safe contraception methods during treatment as the drug can cause feminization of the male fetus if taken throughout pregnancy. Another possible concern for this treatment is the slight rise of estrogen levels due to aromatase conversion of testosterone to estradiol. For this reason this treatment is not advisable in females with a family or personal history of breast cancer.

\subsection{Dutasteride}

Dutasteride is a type one and two 5 alpha-reductase enzyme inhibitor. It inhibits the conversion of testosterone to dihydrotestosterone. There are limited data about the use of this drug in women. There is one case report of good response after 6 months of treatment with $0.5 \mathrm{mg} / \mathrm{d}$ of Dutasteride in a female patient who ceased to benefit from finasteride (57). Dr Camacho (58) reports improvement in $60 \%$ of 25 postmenopausal women with FPHL in the first year and $80 \%$ in the second year using very high dosages $(0.25 \mathrm{mg} / \mathrm{dL})$ of Dutasteride. Still according to the above mentioned author the association of Dutasteride $0.5 \mathrm{mg} / \mathrm{d}$ with Finasteride $2.5 \mathrm{mg} / \mathrm{d}$ was effective in a off-label study involving 14 postmenopausal women with FPHL and 5 premenopausal women with FPHL, hirsutism and nodulocystic acne (59).

A recent controlled study of 126 female patients evaluated the efficacy of locally injected Dutasteride in FPHL. Treatment was delivered by mesotherapy intradermally in the vertex. The solution contained $0.5 \mathrm{mg}$ of Dutasteride, $20 \mathrm{mg}$ of biotin, $200 \mathrm{mg}$ of pyridoxin and $500 \mathrm{mg}$ of D-panthenol in $2 \mathrm{ml}$. Injections were repeated weekly for 8 weeks than every 2 weeks, for 4 weeks and a last application at 16 weeks. Photographic improvement occured in $62.8 \%$ of treated patients at the 18 th week (60).

\subsection{Estrogens}

Estrogens have an uncertain role in human hair growth. The hair follicle has different estrogen receptors: alpha and beta. The beta receptor is the most common one present in the scalp and in general it suppresses cellular function in the hair follicle. Studies in vitro are inconclusive and they show that estrogens may have opposite effects in male scalp hair, where they induce stimulation, versus female scalp hair where they inhibit hair elongation (61, 62). Precursor androgens can be transformed into estrogens in the hair follicle (due to the presence of aromatase and 17-hydroxy steroid dehydrogenase in loco) (63) and estrogens may affect the amount of DHT by affecting the function of the 5-alpha reductase enzyme (64). It has been suggested that a low estrogens to androgens ratio could favour the development of the disease in the genetically susceptible individuals (65). Controlled studies regarding efficacy of topical estrogens for hair loss show controversial results (66-68).

\subsection{Lasers and Light Treatments}

Lasers and light treatments are monochromatic lights that utilize wavelengths between 600 to $1,400 \mathrm{~nm}$, in the red/infrared spectrum (69). There is some evidence that light treatments can stimulate hair growth and the mechanism by which this happens is uncertain (70). The light treatment effects might be attributed to the absorption 
of red/infrared light by the skin which than is absorbed by the cellular respiratory chain (71). The Lasercomb Hair MaxR is a portable laser device that uses a wavelenght of $655 \mathrm{~nm}$ widely marketed for patients as a hair regrowth device. There is one controlled study in males showing efficacy of this technology (72) but there are no published studies in women.

\subsection{Prostaglandin Analogs}

latanoprost and bimatoprost were initially developed for eye glaucoma and one side effect noticed was the growth of eye lashes. There is one study in men showing that lanatoprost $0.1 \%$ increased scalp hair density compared to baseline and placebo (73) but the study included only 16 male patients and the medication was applied to a very small area of the scalp. Different classes of prostaglandins seem to have opposite actions in the hair follicle.

\subsection{Hair Transplantation}

When the loss of hair has been stabilized in patients over 25 years old, hair transplantantion is an alternative. The gold standard technique is the follicular unit transplantation, because of a better outcome in terms of natural architecture and final aspect (74). The hair follicles are implanted individually following the patients natural hair line. It is a multi-step procedure that should be performed by an experienced surgical team. The results will depend on sufficient donor area, number of transplanted hairs, the quality of the hair harvested and the recipient area. The most common problems encountered in hair transplantion in women are related to insufficient hair donor areas, the need for magnification to insert the grafts between the existing hair follicles present in the recipient area and temporary worsening of global aspect after the transplant.

\section{General Care}

Patients should maintain a healthy and varied diet to guarantee adequate iron, vitamins and protein intake. They should avoid local treatments and manipulation of the scalp that could cause hair breakage (such as straightening, perming and hair extensions), which can mimic hair loss. If possible, avoid medications prone to cause hair shedding and other factors that could negatively impact the hair growth, such as smoking and sun exposure of the scalp $(75,76)$.

\section{Conclusions}

FPHL is a common condition that cause considerable distress to patients. Recent data indicate that FPHL is not just a cosmetic problem but it is significantly associated with metabolic syndrome and its medical complications. Prompt diagnosis, evaluation of comorbidities and treatment are important and management of this condition often involves a multidisciplinary approach.

\section{Acknowledgements}

None Declared.

\section{Authors' Contribution}

Dr. Antonella Tosti: conception, design, review and general supervision of study. Dr. Ingrid Herskovitz: research, acquisiton, analysis and interpretation of data, drafting of the study.

\section{Financial Disclosure}

The authors have no ficancial disclosures to reveal

\section{Funding/Support}

There is no Funding/Support.

\section{References}

1. Blume-Peytavi U, Blumeyer A, Tosti A, Finner A, Marmol V, Trakatelli M, et al. S1 guideline for diagnostic evaluation in androgenetic alopecia in men, women and adolescents. Br J Dermatol. 2011;164(1):5-15

2. Leavitt M. Understanding and management of female pattern alopecia. Facial Plast Surg. 2008;24(4):414-27.

3. Hadshiew IM, Foitzik K, Arck PC, Paus R. Burden of hair loss: stress and the underestimated psychosocial impact of telogen effluvium and androgenetic alopecia. J Invest Dermatol. 2004;123(3):455-7.

4. Birch MP, Messenger JF, Messenger AG. Hair density, hair diameter and the prevalence of female pattern hair loss. BrJ Dermatol. 2001;144(2):297-304.

5. Norwood OT. Incidence of female androgenetic alopecia (female pattern alopecia). Dermatol Surg. 2001;27(1):53-4.

6. Futterweit W, Dunaif A, Yeh HC, Kingsley P. The prevalence of hyperandrogenism in 109 consecutive female patients with diffuse alopecia. J Am Acad Dermatol.1988;19(5 Pt 1):831-6.

7. Montalto J, Whorwood CB, Funder JW, Yong AB, Callan A, Davies $\mathrm{HE}$, et al. Plasma C19 steroid sulphate levels and indices of androgen bioavailability in female pattern androgenic alopecia. Clin Endocrinol (Oxf). 1990;32(1):1-12.

8. Olsen EA. Female pattern hair loss. J Am Acad Dermatol. 2001;45(3 Suppl):S70-80.

9. Wilson JD, Griffin JE, Leshin M, MacDonald PC, JB Stanbury JB Wyngaarden, DSFredrickson, JL Goldstein, and MS Brown editor(s). The androgen resistance syndromes: 5a-reductase deficiency, testicular feminization, and related disorders. McGraw-Hill, New York; 1983.

10. Glaser RL, Dimitrakakis C, Messenger AG. Improvement in scalp hair growth in androgen-deficient women treated with testosterone: a questionnaire study. Br J Dermatol. 2012;166(2):274-8.

11. Karrer-Voegeli S, Rey F, Reymond MJ, Meuwly JY, Gaillard RC, Gomez F. Androgen dependence of hirsutism, acne, and alopecia in women: retrospective analysis of 228 patients investigated for hyperandrogenism. Medicine (Baltimore). 2009;88(1):32-45.

12. Inui S, Itami S. Molecular basis of androgenetic alopecia: From androgen to paracrine mediators through dermal papilla.J Dermatol Sci. 2011;61(1):1-6.

13. Winiarska A, Mandt N, Kamp H, Hossini A, Seltmann H, Zouboulis CC, et al. Effect of 5alpha-dihydrotestosterone and testosterone on apoptosis in human dermal papilla cells. Skin Pharmacol Physiol. 2006;19(6):311-21.

14. Redler S, Brockschmidt FF, Tazi-Ahnini R, Drichel D, Birch MP, Dobson $\mathrm{K}$, et al. Investigation of the male pattern baldness major genetic susceptibility loci AR/EDA2R and 20p11 in female pattern hair loss. Br J Dermatol. 2012;166(6):1314-8. 
Herskovitz I et al.

15. Yip L, Zaloumis S, Irwin D, Severi G, Hopper J, Giles G, et al. Genewide association study between the aromatase gene (CYP19A1) and female pattern hair loss. Br J Dermatol. 2009;161(2):289-94.

16. Redler S, Birch MP, Drichel D, Dobson K, Brockschmidt FF, Tazi-Ahnini $\mathrm{R}$, et al. Investigation of variants of the aromatase gene (CYP19A1) in female pattern hair loss. Br J Dermatol. 2011;165(3):703-5.

17. Redler S, Tazi-Ahnini R, Drichel D, Birch MP, Brockschmidt FF, Dobson K, et al. Selected variants of the steroid-5-alpha-reductase isoforms SRD5A1 and SRD5A2 and the sex steroid hormone receptors ESR1, ESR2 and PGR: no association with female pattern hair loss identified. Exp Dermatol. 2012;21(5):390-3.

18. Mahmoudi H, Redler S, Birch P, Drichel D, Dobson K, Tazi-Ahnini $\mathrm{R}$, et al. Selected variants of the melanocortin 4 receptor gene (MC4R) do not confer susceptibility to female pattern hair loss. Arch Dermatol Res. 2013;305(3):249-53.

19. Ludwig E. Classification of the types of androgenetic alopecia (common baldness) occurring in the female sex. Br J Dermatol. 1977;97(3):247-54.

20. Olsen EA. Androgenetic alopecia. In: Disorders of hair growth: diagnosis and treatment.. New York: McGraw-Hill; 1994. p. 257-283.

21. Venning VA, Dawber RP. Patterned androgenic alopecia in women. J Am Acad Dermatol.1988;18(5 Pt1):1073-7.

22. Miteva M, Tosti A. Hair and scalp dermatoscopy.JAm Acad Dermatol. 2012;67(5):1040-8.

23. Ross EK, Vincenzi C, Tosti A. Videodermoscopy in the evaluation of hair and scalp disorders. J Am Acad Dermatol. 2006;55(5):799806.

24. de Lacharriere O, Deloche C, Misciali C, Piraccini BM, Vincenzi C, Bastien P, et al. Hair diameter diversity: a clinical sign reflecting the follicle miniaturization. Arch Dermatol. 2001;137(5):641-6.

25. Arias-Santiago S, Gutierrez-Salmeron MT, Castellote-Caballero L, Buendia-Eisman A, Naranjo-Sintes R. Androgenetic alopecia and cardiovascular risk factors in men and women: a comparative study. J Am Acad Dermatol. 2010;63(3):420-9.

26. Yi SM, Son SW, Lee KG, Kim SH, Lee SK, Cho ER, et al. Genderspecific association of androgenetic alopecia with metabolic syndrome in a middle-aged Korean population. Br J Dermatol. 2012;167(2):306-13.

27. Whiting DA. Chronic telogen effluvium: increased scalp hair shedding in middle-aged women. J Am Acad Dermatol. 1996;35(6):899-906.

28. Harrison S, Sinclair R. Telogen effluvium. Clin Exp Dermatol. 2002;27(5):389-5.

29. Gilmore S, Sinclair R. Chronic telogen effluvium is due to a reduction in the variance of anagen duration. Australas J Dermatol. 2010;51(3):163-7.

30. Kluger N, Jacot W, Frouin E, Rigau V, Poujol S, Dereure O, et al. Permanent scalp alopecia related to breast cancer chemotherapy by sequential fluorouracil/epirubicin/cyclophosphamide (FEC) and docetaxel: a prospective study of 20 patients. Ann Oncol. 2012;23(11):2879-84.

31. Palamaras I, Misciali C, Vincenzi C, Robles WS, Tosti A. Permanent chemotherapy-induced alopecia: a review. J Am Acad Dermatol. 2011;64(3):604-6.

32. Miteva M, Misciali C, Fanti PA, Vincenzi C, Romanelli P, Tosti A. Permanent alopecia after systemic chemotherapy: a clinicopathological study of 10 cases. Am J Dermatopathol. 2011;33(4):345-50.

33. Miteva M, Misciali C, Fanti PA, Tosti A. Histopathologic features of alopecia areata incognito: a review of 46 cases. J Cutan Pathol. 2012;39(6):596-602.

34. Rebora A. Alopecia areata incognita: a comment. Clinics (Sao Paulo). 2011;66(8):1481-2.

35. Tosti A, Whiting D, Iorizzo M, Pazzaglia M, Misciali C, Vincenzi C, et al. The role of scalp dermoscopy in the diagnosis of alopecia areata incognita. JAm Acad Dermatol. 2008;59(1):64-7.

36. Kossard S. Postmenopausal frontal fibrosing alopecia. Scarring alopecia in a pattern distribution. Arch Dermatol.1994;130(6):7704.

37. Chew AL, Bashir SJ, Wain EM, Fenton DA, Stefanato CM. Expanding the spectrum of frontal fibrosing alopecia: a unifying concept. J Am Acad Dermatol. 2010;63(4):653-60.
38. MacDonald A, Clark C, Holmes S. Frontal fibrosing alopecia: a review of 60 cases. J Am Acad Dermatol. 2012;67(5):955-61.

39. Tosti A, Piraccini BM, Iorizzo M, Misciali C. Frontal fibrosing alopecia in postmenopausal women. J Am Acad Dermatol. 2005;52(1):55-60.

40. Blumeyer A, Tosti A, Messenger A, Reygagne P, Del Marmol V, Spuls PI, et al. Evidence-based (S3) guideline for the treatment of androgenetic alopecia in women and in men.J Dtsch Dermatol Ges. 2011;9 Suppl 6:S1-57.

41. Whiting DA, Jacobson C. Treatment of female androgenetic alopecia with minoxidil 2\%. Int J Dermatol. 1992;31(11):800-4.

42. Blume-Peytavi U, Hillmann K, Dietz E, Canfield D, Garcia Bartels N. A randomized, single-blind trial of 5\% minoxidil foam once daily versus $2 \%$ minoxidil solution twice daily in the treatment of androgenetic alopecia in women. J Am Acad Dermatol. 2011;65(6):1126-1134 e2.

43. Peereboom-Wynia JD, van der Willigen AH, van Joost T, Stolz E. The effect of cyproterone acetate on hair roots and hair shaft diameter in androgenetic alopecia in females. Acta Derm Venereol. 1989;69(5):395-8.

44. Vexiau P, Chaspoux C, Boudou P, Fiet J, Jouanique C, Hardy N, et al. Effects of minoxidil $2 \%$ vs. cyproterone acetate treatment on female androgenetic alopecia: a controlled, 12-month randomized trial. Br J Dermatol. 2002;146(6):992-9.

45. Shaw JC. Antiandrogen therapy in dermatology. Int J Dermatol. 1996;35(11):770-8.

46. Christy NA, Franks AS, Cross LB. Spironolactone for hirsutism in polycystic ovary syndrome. Ann Pharmacother. 2005;39(9):1517-21.

47. Shaw JC, White LE. Long-term safety of spironolactone in acne: results of an 8-year followup study.J Cutan Med Surg. 2002;6(6):5415.

48. Shapiro J. Clinical practice. Hair loss in women. $N$ Engl J Med. 2007;357(16):1620-30.

49. Sinclair R, Wewerinke M, Jolley D. Treatment of female pattern hair loss with oral antiandrogens. BrJ Dermatol. 2005;152(3):46673.

50. Rushton D HUGH, Futterweit WALTER, Kingsley DAVID H, Kingsley Philip, Norris Michael J. Quantitative assessment of spironolactone treatment in women with diffuse androgen-dependent alopecia. J Soc Cosmet Chem. 1991;42:317-325.

51. Paradisi R, Porcu E, Fabbri R, Seracchioli R, Battaglia C, Venturoli S. Prospective cohort study on the effects and tolerability of flutamide in patients with female pattern hair loss. Ann Pharmacother. 2011;45(4):469-75.

52. Bruni V, Peruzzi E, Dei M, Nannini S, Seravalli V, Sisti G, et al Hepatotoxicity with low- and ultralow-dose flutamide: a surveillance study on 203 hyperandrogenic young females. Fertil Steril. 2012;98(4):1047-52.

53. Price VH, Roberts JL, Hordinsky M, Olsen EA, Savin R, Bergfeld W, et al. Lack of efficacy of finasteride in postmenopausal women with androgenetic alopecia. J Am Acad Dermatol. 2000;43(5 Pt 1):768-76.

54. Iorizzo M, Vincenzi C, Voudouris S, Piraccini BM, Tosti A. Finasteride treatment of female pattern hair loss. Arch Dermatol. 2006;142(3):298-302.

55. Kohler C, Tschumi K, Bodmer C, Schneiter M, Birkhaeuser M. Effect of finasteride $5 \mathrm{mg}$ (Proscar) on acne and alopecia in female patients with normal serum levels of free testosterone. Gynecol Endocrinol. 2007;23(3):142-5.

56. Trueb RM. Finasteride treatment of patterned hair loss in normoandrogenic postmenopausal women. Dermatology. 2004;209(3):202-7.

57. Olszewska M, Rudnicka L. Effective treatment of female androgenic alopecia with dutasteride. J Drugs Dermatol. 2005;4(5):63740.

58. Camacho F, Tosti A. [Medical treatment of female alopecia]. Monogr Dermatol. 2005;18(6):92.

59. Camacho-Martínez Francisco M, editor. Hair loss in women. Semin Cutan Med Surg.; 2009: Elsevier. p. 19-32.

60. Moftah N, Abd-Elaziz G, Ahmed N, Hamed Y, Ghannam B, Ibrahim M. Mesotherapy using dutasteride-containing preparation in treatment of female pattern hair loss: photographic, morpho- 
metric and ultrustructural evaluation. J Eur Acad Dermatol Venereol. 2013;27(6):686-93.

61. Kondo S, Hozumi Y, Aso K. Organ culture of human scalp hair follicles: effect of testosterone and oestrogen on hair growth. Arch Dermatol Res. 1990;282(7):442-5.

62. Nelson L, Messenger A, Karoo R, Thornton JW. 17beta-eatradiol but not 17alpha-estradiol inhibits human hair growth in whole follicle organ culture. J Invest Dermatol. 2003;121(1):821a.

63. Thornton MJ. The biological actions of estrogens on skin. Exp Dermatol. 2002;11(6):487-502.

64. Niiyama S, Happle R, Hoffmann R. Influence of estrogens on the androgen metabolism in different subunits of human hair follicles. Eur J Dermatol. 2001;11(3):195-8.

65. Riedel-Baima B, Riedel A. Female pattern hair loss may be triggered by low oestrogen to androgen ratio. Endocr Regul. 2008;42(1):13-6.

66. Blume-Peytavi U, Kunte C, Krisp A, Garcia Bartels N, Ellwanger U Hoffmann R. Comparison of the efficacy and safety of topical minoxidil and topical alfatradiol in the treatment of androgenetic alopecia in women.J Dtsch Dermatol Ges. 2007;5(5):391-5.

67. Gassmueller J, Hoffmann R, Webster A. Topical fulvestrant solution has no effect on male and postmenopausal female androgenetic alopecia: results from two randomized, proof-of-concept studies. Br J Dermatol. 2008;158(1):109-15.

68. Georgala S, Katoulis AC, Georgala C, Moussatou V, Bozi E, Stavrianeas NG. Topical estrogen therapy for androgenetic alopecia in menopausal females. Dermatology. 2004;208(2):178-9.

69. Hamblin Michael R, Demidova Tatiana N, editors. Mechanisms of low level light therapy. Biomedical Optics 2006.; 2006: International Society for Optics and Photonics. p. 614001-614001-12.

70. Avram MR, Leonard RT, Jr, Epstein ES, Williams JL, Bauman AJ. The current role of laser/light sources in the treatment of male and female pattern hair loss. J Cosmet Laser Ther. 2007;9(1):27-8.

71. Karu T. Laser biostimulation: a photobiological phenomenon. $J$ Photochem Photobiol B. 1989;3(4):638-40.

72. Leavitt M, Charles G, Heyman E, Michaels D. HairMax LaserComb laser phototherapy device in the treatment of male androgenetic alopecia: A randomized, double-blind, sham device-controlled, multicentre trial. Clin Drug Investig. 2009;29(5):283-92.

73. Blume-Peytavi U, Lonnfors S, Hillmann K, Garcia Bartels N. A ran domized double-blind placebo-controlled pilot study to assess the efficacy of a 24-week topical treatment by latanoprost $0.1 \%$ on hair growth and pigmentation in healthy volunteers with androgenetic alopecia. JAm Acad Dermatol. 2012;66(5):794-800.

74. Caroli S, Pathomvanich D, Amonpattana K, Kumar A. Current status of hair restoration surgery. Int Surg. 2011;96(4):345-51.

75. Trueb RM. Association between smoking and hair loss: another opportunity for health education against smoking? Dermatology. 2003;206(3):189-91.

76. Trueb RM. Oxidative stress in ageing of hair. Int $J$ Trichology. 2009;1(1):6-14 